\title{
Mechanical Control of Rate Processes: Effect of Ligand Steric Bulk on CO Exchange in Trisubstituted Tetrairidium Cluster Catalysts
}

\author{
Andrew Solovyov, Mizuho Yabushita and Alexander Katz* \\ Department of Chemical and Biomolecular Engineering, University of California at Berkeley, \\ Berkeley, California 94720-1462, United States \\ * email: askatz@berkeley.edu
}

\section{Supporting Information}

Fig. S1 Structures of clusters 1-3.

Fig.S2 ${ }^{1} \mathrm{H}$ NMR (DRX500, $\mathrm{CDCl}_{3}$ ) spectrum of 1 at $293 \mathrm{~K}$.

Fig.S3 ${ }^{31} \mathrm{P}$ NMR (AV600, toluene- $d_{8}$ ) spectrum of 1 at $293 \mathrm{~K}$.

Fig.S4 ${ }^{13} \mathrm{C}$ NMR (AV600, toluene- $d_{8}$ ) spectrum of 1 at $293 \mathrm{~K}$.

Fig.S5 ${ }^{13} \mathrm{C}$ NMR (AV600, toluene- $d_{8}$ ) spectrum of 1 (carbonyl region) at $293 \mathrm{~K}$.

Fig.S6 ${ }^{13} \mathrm{C}$ NMR (AV600, toluene- $d_{8}$ ) spectrum of 1 (carbonyl region) at $323 \mathrm{~K}$.

Fig.S7 ${ }^{13} \mathrm{C}$ NMR (AV600, toluene- $d_{8}$ ) spectrum of 1 (carbonyl region) at $353 \mathrm{~K}$.

Fig.S8 ${ }^{1} \mathrm{H}$ NMR (AV600, toluene- $d_{8}$ ) spectrum of 2 at $293 \mathrm{~K}$.

Fig.S9 ${ }^{31} \mathrm{P}$ NMR (AV600, toluene- $d_{8}$ ) spectrum of 2 at $293 \mathrm{~K}$.

Fig.S10 ${ }^{31}$ P VT NMR (AV600, toluene- $d_{8}$ ) at $293 \mathrm{~K}$ (blue) and $353 \mathrm{~K}$ (red) spectrum of 2.

Fig.S1 ${ }^{13} \mathrm{C}$ qNMR (AV600, toluene- $d_{8}$ ) spectrum of 2 at $293 \mathrm{~K}$.

Fig.S12 ${ }^{13} \mathrm{C}$ qNMR (AV600, toluene- $d_{8}$ ) spectrum of 2 (carbonyl region) at $293 \mathrm{~K}$.

Fig.S13 ${ }^{13} \mathrm{C}$ NMR (AV600, toluene- $d_{8}$ ) spectrum of 2 (carbonyl region) at $323 \mathrm{~K}$.

Fig.S14 ${ }^{13} \mathrm{C}$ NMR (AV600, toluene- $d_{8}$ ) spectrum of 2 (carbonyl region) at $353 \mathrm{~K}$.

Fig.S15 ${ }^{1} \mathrm{H}$ NMR (AV600, $\mathrm{CDCl}_{3}$ ) spectrum of 3 at $293 \mathrm{~K}$.

Fig.S16 ${ }^{13} \mathrm{C}$ qNMR (AV600, toluene- $d_{8}$ ) spectrum of 3 at $293 \mathrm{~K}$.

Fig.S17 ${ }^{13} \mathrm{C}$ NMR (AV600, toluene- $d_{8}$ ) spectrum of 3 (aliphatic region) at 293K.

Fig.S18 ${ }^{13} \mathrm{C}$ qNMR (AV600, toluene- $d_{8}$ ) spectrum of 3 (aromatic region) at $293 \mathrm{~K}$.

Fig.S19 ${ }^{13} \mathrm{C}$ qNMR (AV600, toluene- $d_{8}$ ) spectrum of 3 (carbonyl region) at $293 \mathrm{~K}$.

Fig.S20 ${ }^{13} \mathrm{C}$ qNMR (AV600, toluene- $d_{8}$ ) spectrum of 3 (carbonyl region) at $323 \mathrm{~K}$.

Fig.S21 ${ }^{13} \mathrm{C}$ qNMR (AV600, toluene- $d_{8}$ ) spectrum of 3 (carbonyl region) at $353 \mathrm{~K}$. 
Fig. S22. ${ }^{13} \mathrm{C}$ qNMR (AV600, toluene- $d_{8}$ ) spectrum of $\mathbf{3}$ (carbonyl region) at $293 \mathrm{~K}$ (green), 323 $\mathrm{K}$ (red) and $353 \mathrm{~K}$ (blue).

Fig.S23 ${ }^{31}$ P VT NMR (AV600, toluene- $d_{8}$ ) spectrum of 3 at $293 \mathrm{~K}$ (red), 353K (blue).

Fig.S24 ${ }^{13} \mathrm{C}$ VT qNMR (AV600, toluene- $d_{8}$ ) spectrum of $\mathbf{3}$ (line shape of bridging carbonyls at $293 \mathrm{~K}$ (blue), $323 \mathrm{~K}$ (red), $353 \mathrm{~K}$ (green).

Fig.S25 ${ }^{13} \mathrm{C}$ VT NMR (AV600, toluene- $d_{8}$ ) spectrum of 2 (line shape of bridging carbonyls at 293 $\mathrm{K}$ (blue), $323 \mathrm{~K}$ (red), $353 \mathrm{~K}$ (green)).

Fig.S26 ${ }^{13} \mathrm{C}$ VT NMR (AV600, toluene- $d_{8}$ ) spectrum of 1 (line shape of bridging carbonyls at 293 K (blue), $323 \mathrm{~K}$ (red), $353 \mathrm{~K}$ (green). 


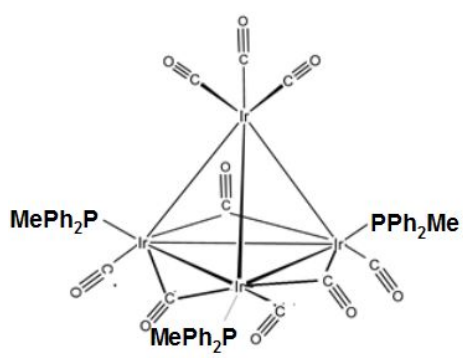

1

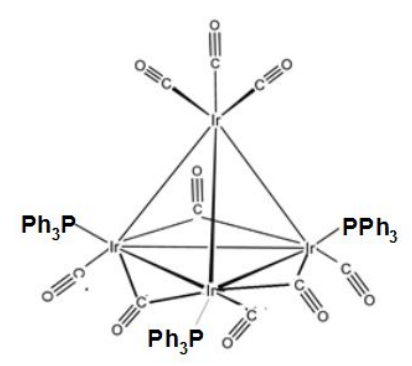

2

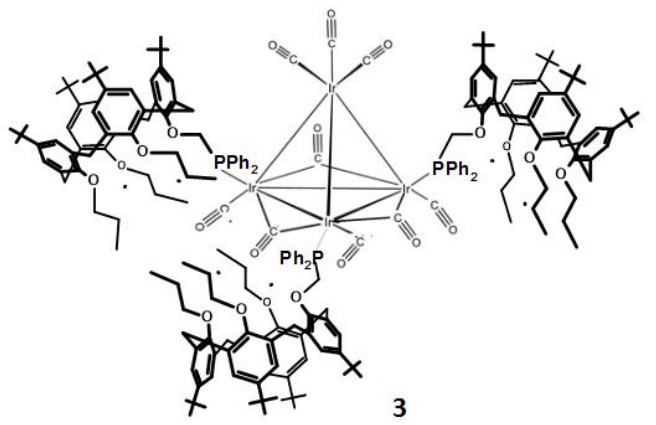

Fig S1. Structures of clusters 1-3.

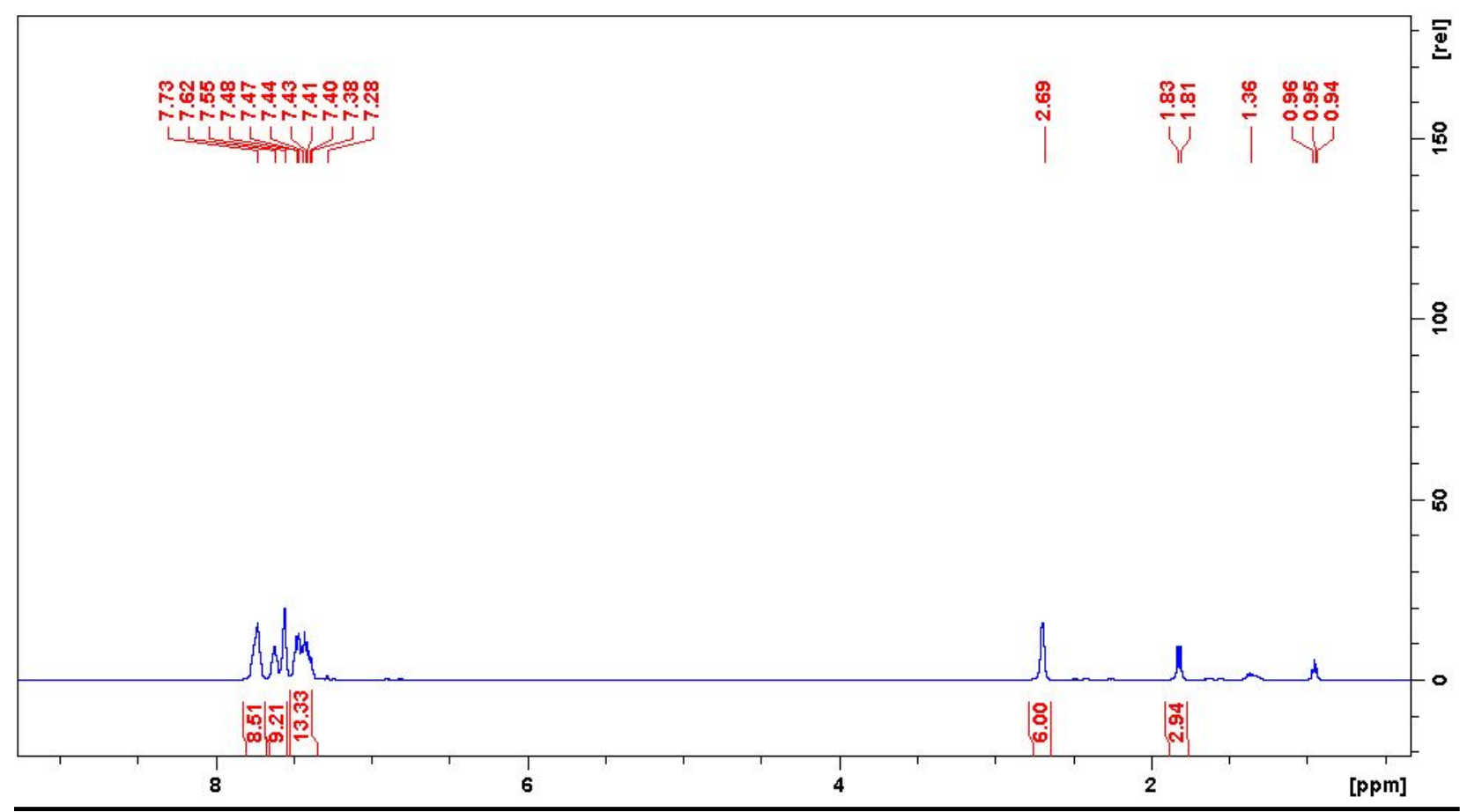

Fig. S2. ${ }^{1} \mathrm{H}$ NMR (DRX500, $\mathrm{CDCl}_{3}$ ) spectrum of 1 at $293 \mathrm{~K}$. 


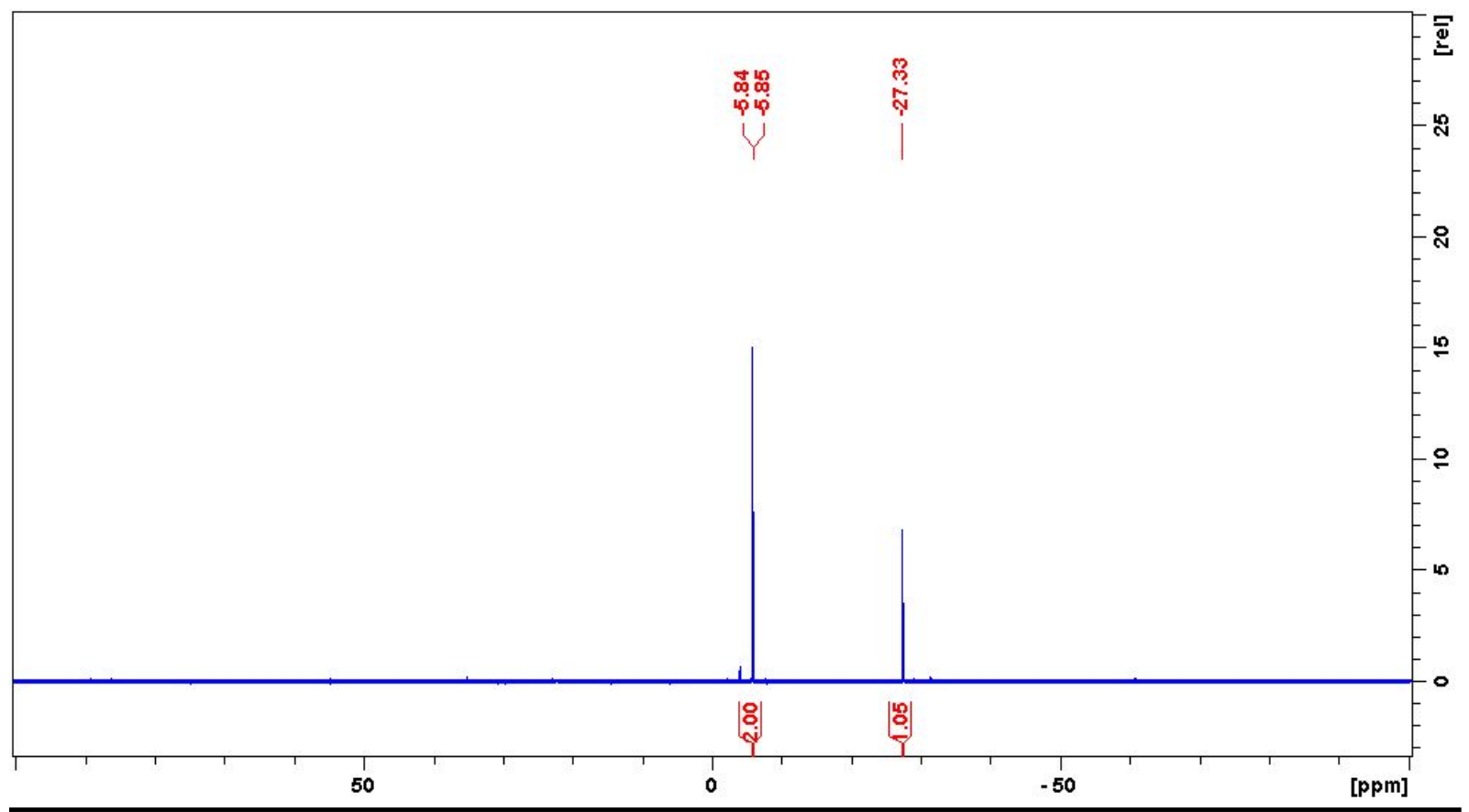

Fig. S3. ${ }^{31} \mathrm{P}$ NMR (AV600, toluene- $d_{8}$ ) spectrum of $\mathbf{1}$ at $293 \mathrm{~K}$.

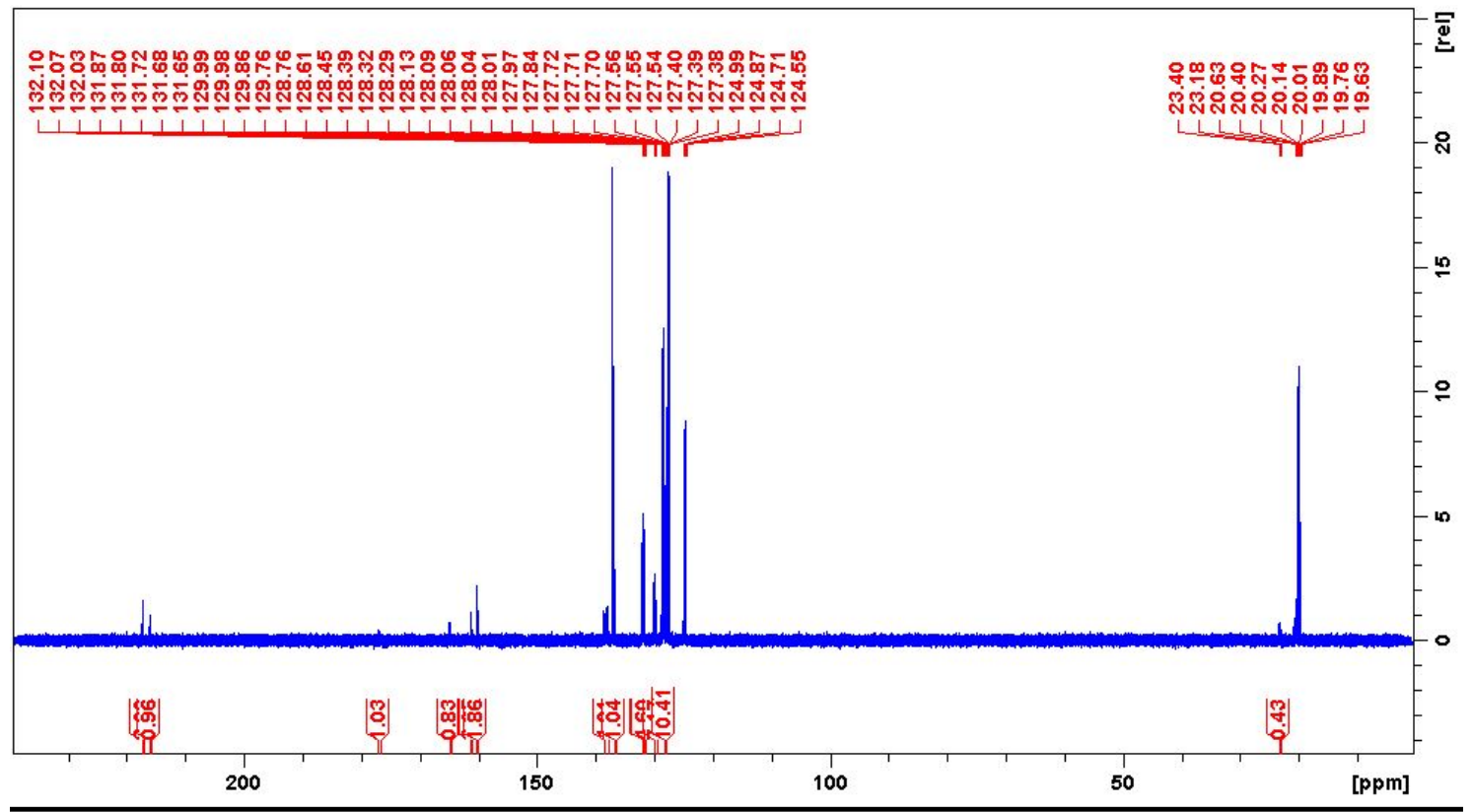

Fig. S4. ${ }^{13} \mathrm{C}$ NMR (AV600, toluene- $d_{8}$ ) spectrum of 1 at $293 \mathrm{~K}$. 


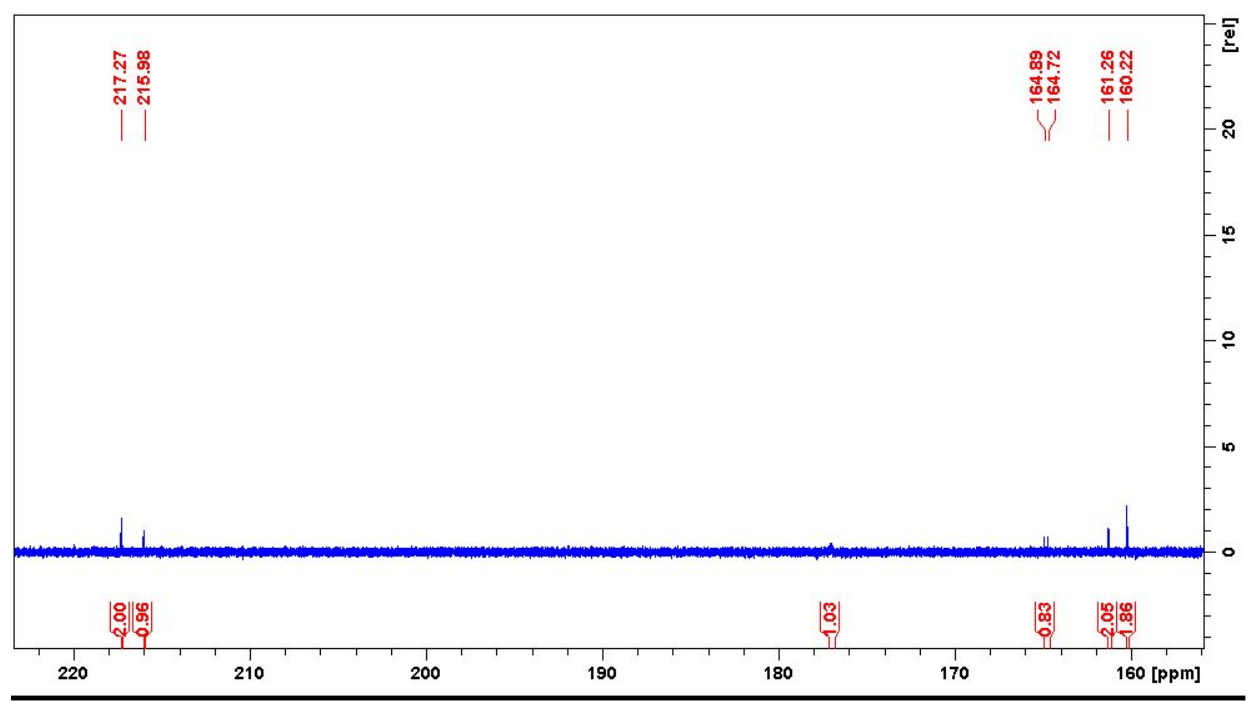

Fig. S5. ${ }^{13} \mathrm{C}$ NMR (AV600, toluene- $d_{8}$ ) spectrum of 1 (carbonyl region) at $293 \mathrm{~K}$.

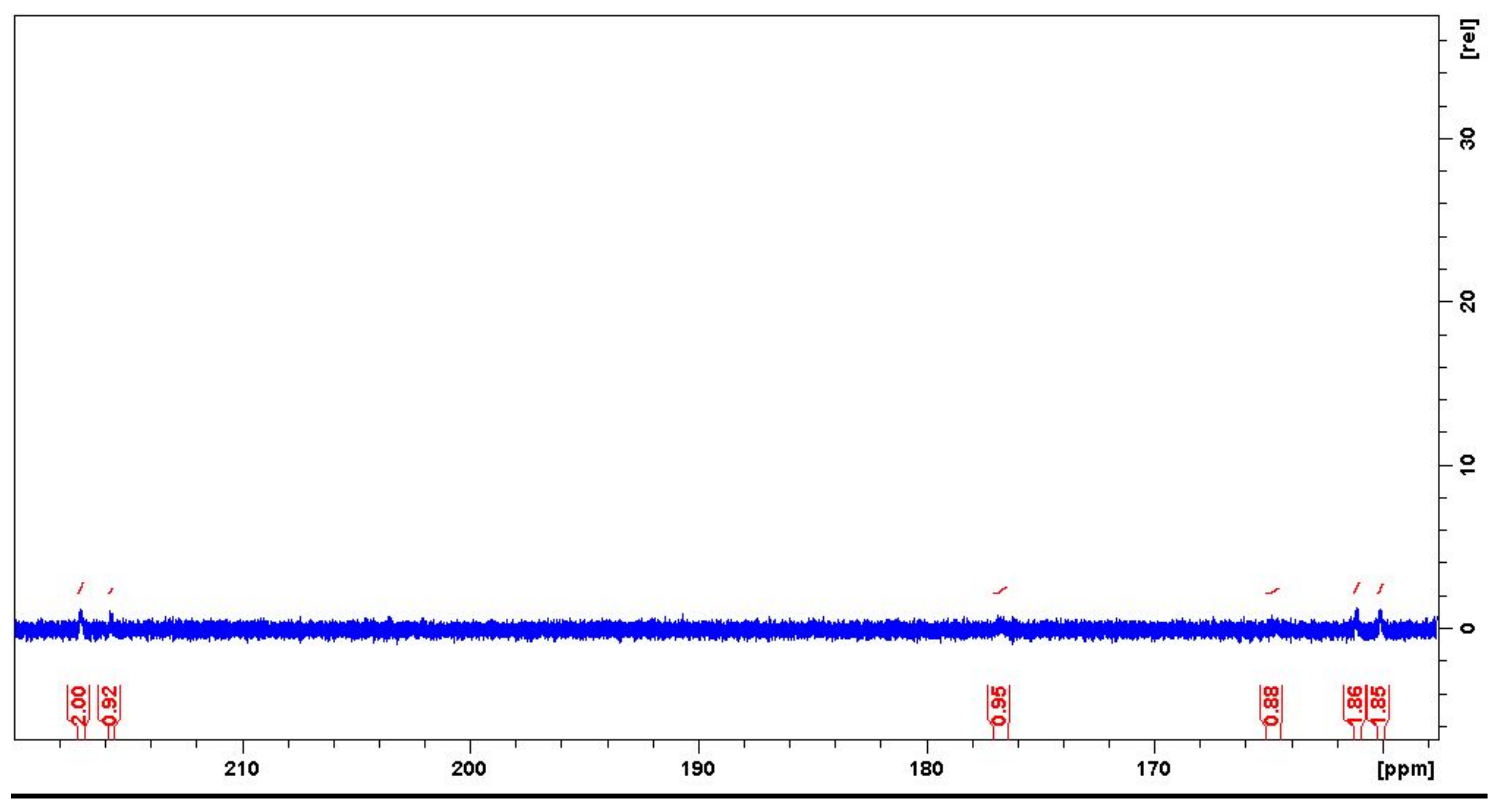

Fig. S6. ${ }^{13} \mathrm{C}$ NMR (AV600, toluene- $d_{8}$ ) spectrum of 1 (carbonyl region) at $323 \mathrm{~K}$. 


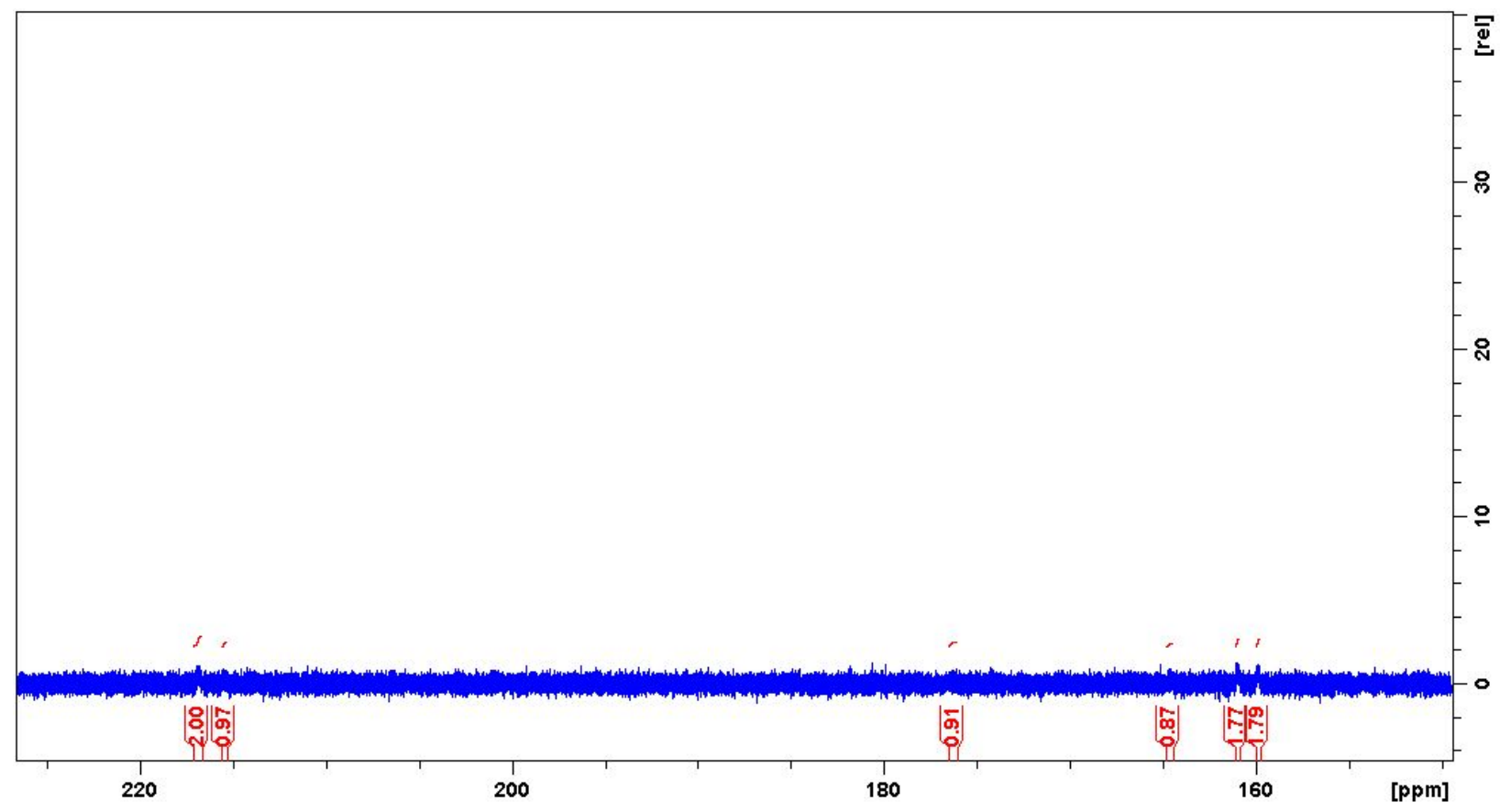

Fig. S7. ${ }^{13} \mathrm{C}$ NMR (AV600, toluene- $d_{8}$ ) spectrum of $\mathbf{1}$ (carbonyl region) at $353 \mathrm{~K}$. 


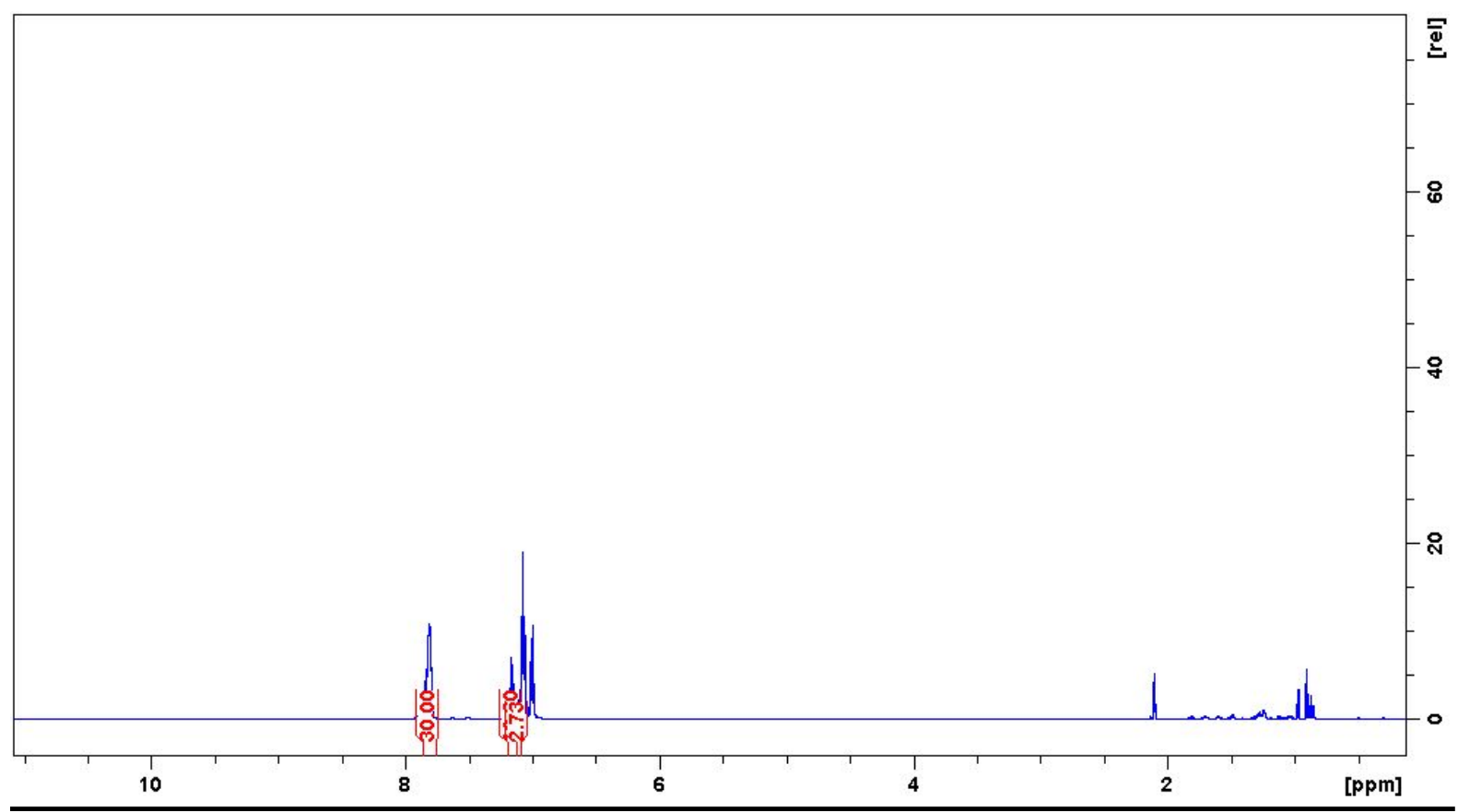

Fig. S8. ${ }^{1} \mathrm{H}$ NMR (AV600, toluene- $d_{8}$ ) spectrum of 2 at $293 \mathrm{~K}$.

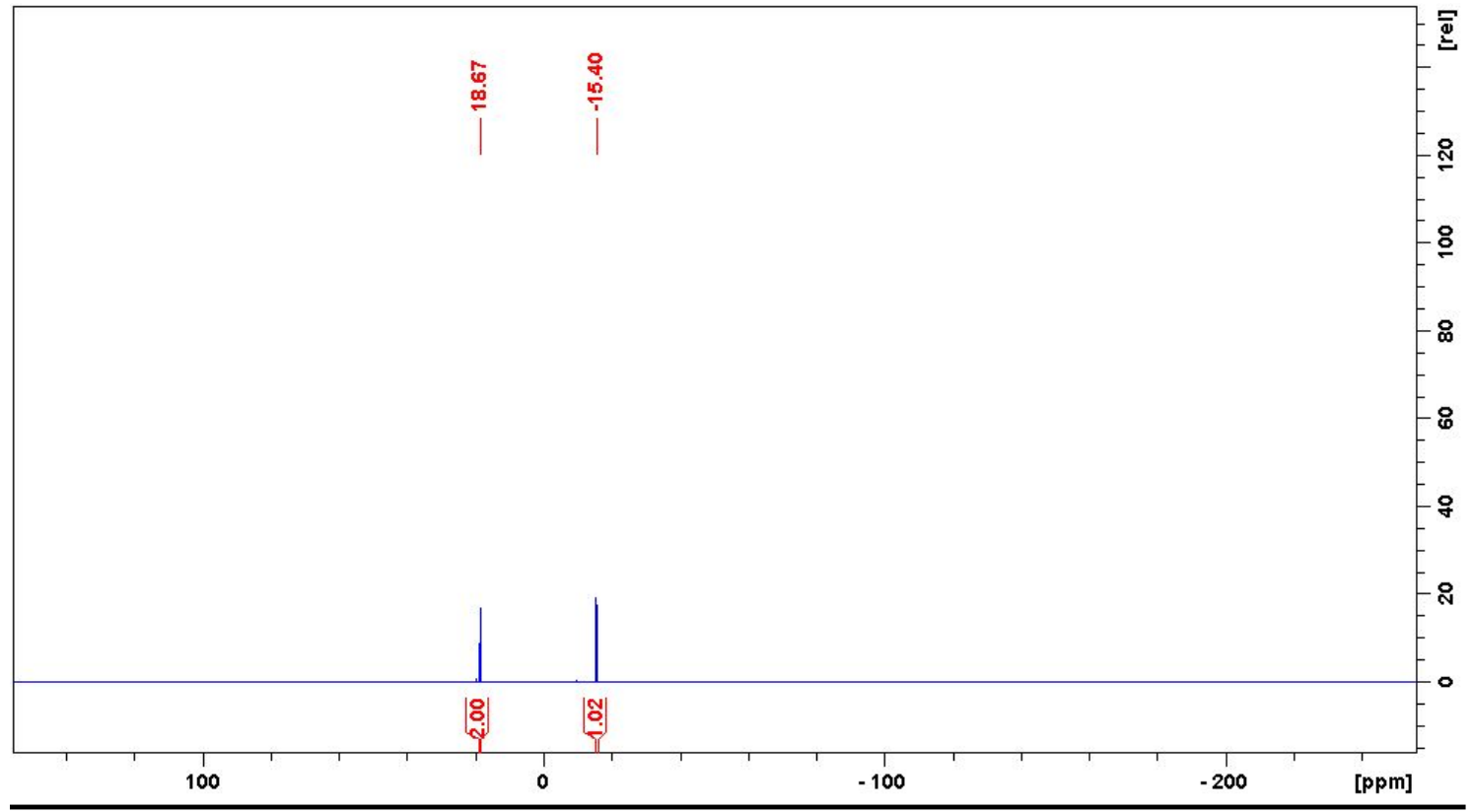

Fig. S9. ${ }^{31} \mathrm{P}$ NMR (AV600, toluene- $d_{8}$ ) spectrum of 2 at $293 \mathrm{~K}$. 


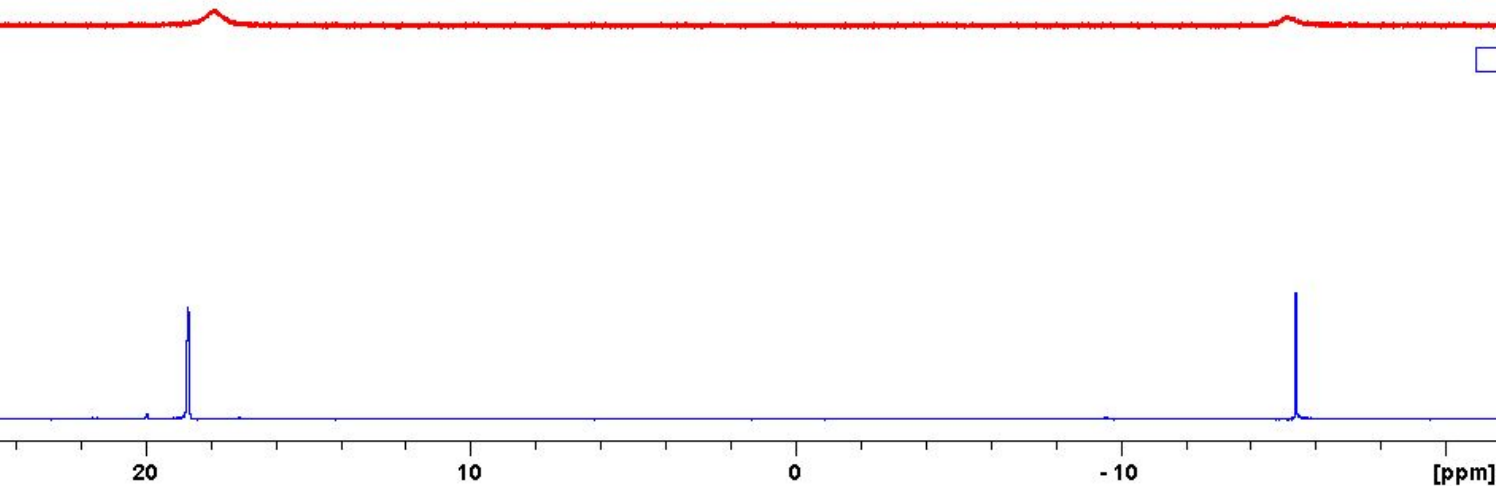

Fig. S10. ${ }^{31} \mathrm{P}$ VT NMR (AV600, toluene- $d_{8}$ ) at $293 \mathrm{~K}$ (blue) and $353 \mathrm{~K}$ (red) spectrum of 2. Similar broadening was also observed for cluster 1 under identical conditions, when comparing spectra at $293 \mathrm{~K}$ and $353 \mathrm{~K}$.

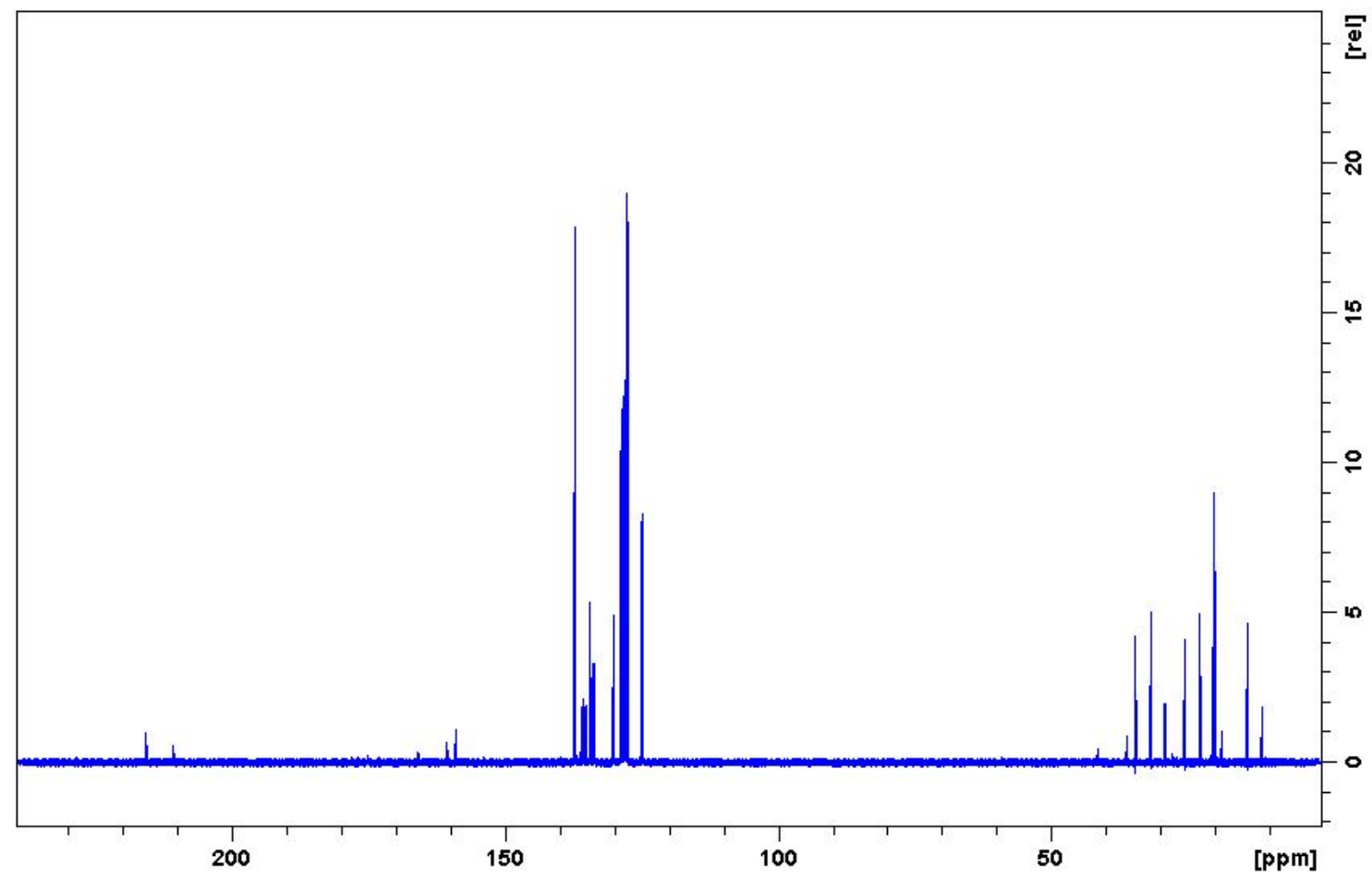

Fig. S11. ${ }^{13} \mathrm{C}$ qNMR (AV600, toluene- $d_{8}$ ) spectrum of 2 at $293 \mathrm{~K}$. 


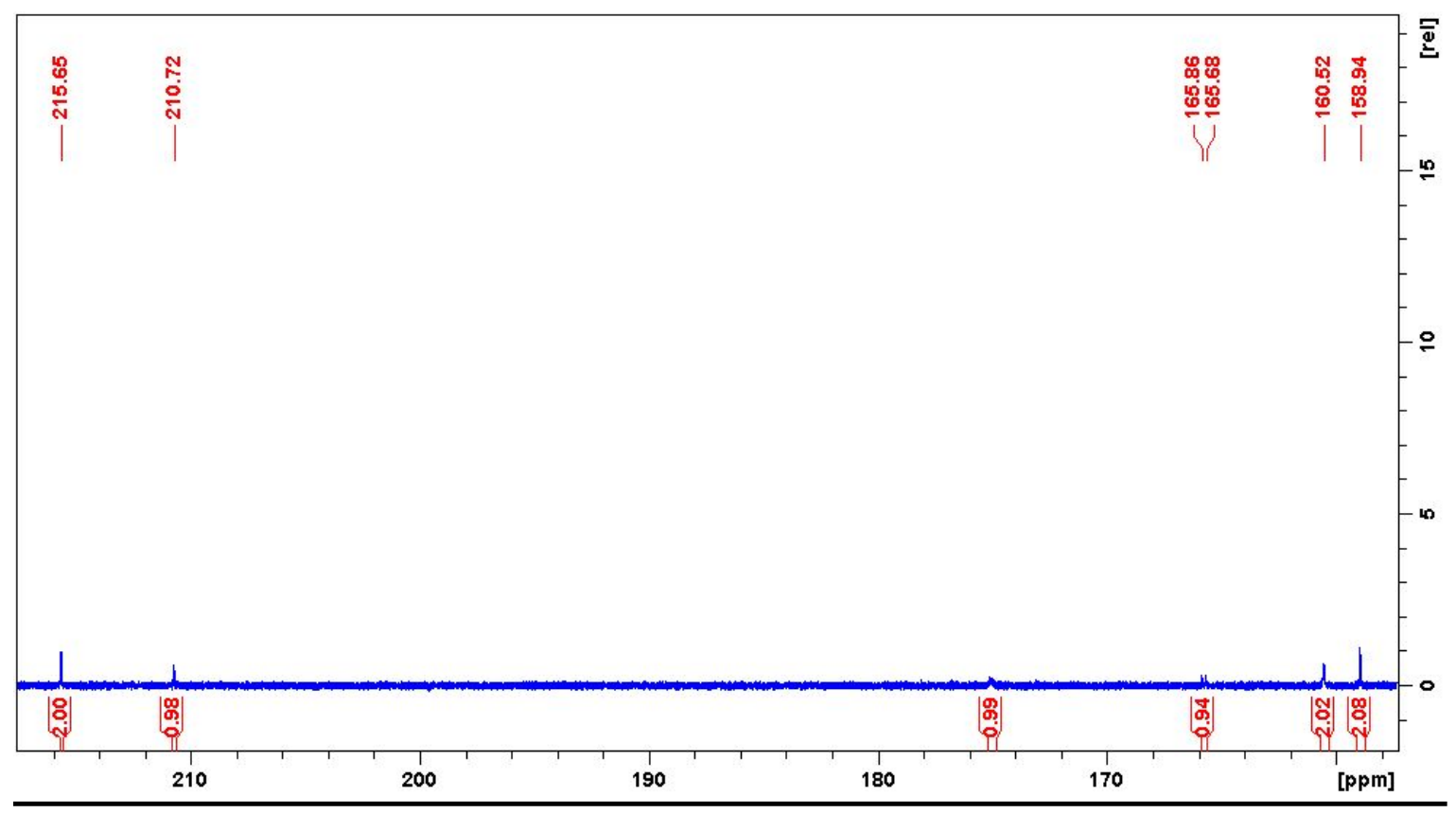

Fig. S12. ${ }^{13} \mathrm{C}$ qNMR (AV600, toluene- $d_{8}$ ) spectrum of 2 (carbonyl region) at $293 \mathrm{~K}$.

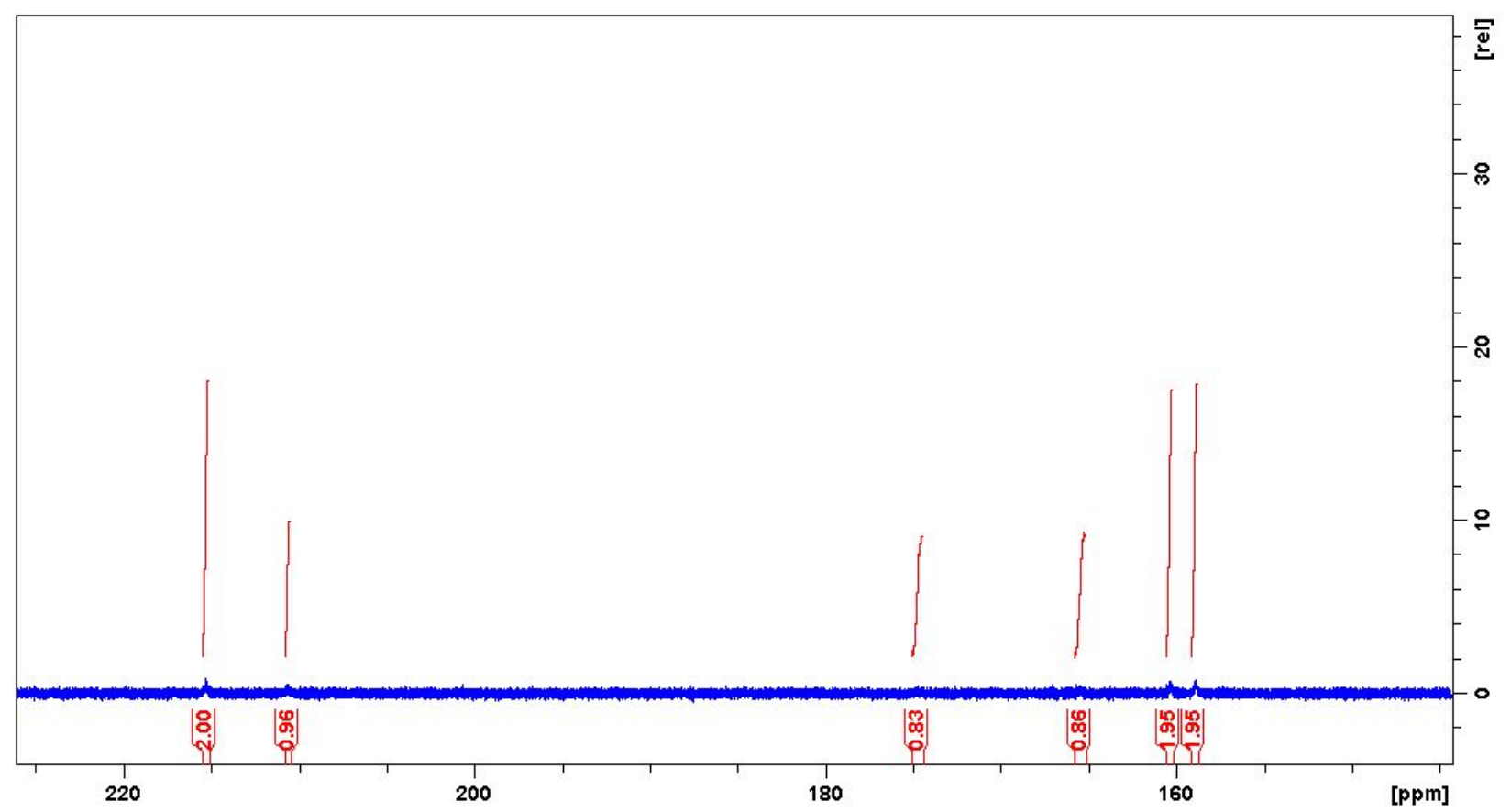

Fig. S13. ${ }^{13} \mathrm{C}$ qNMR (AV600, toluene- $d_{8}$ ) spectrum of 2 (carbonyl region) at $323 \mathrm{~K}$. 


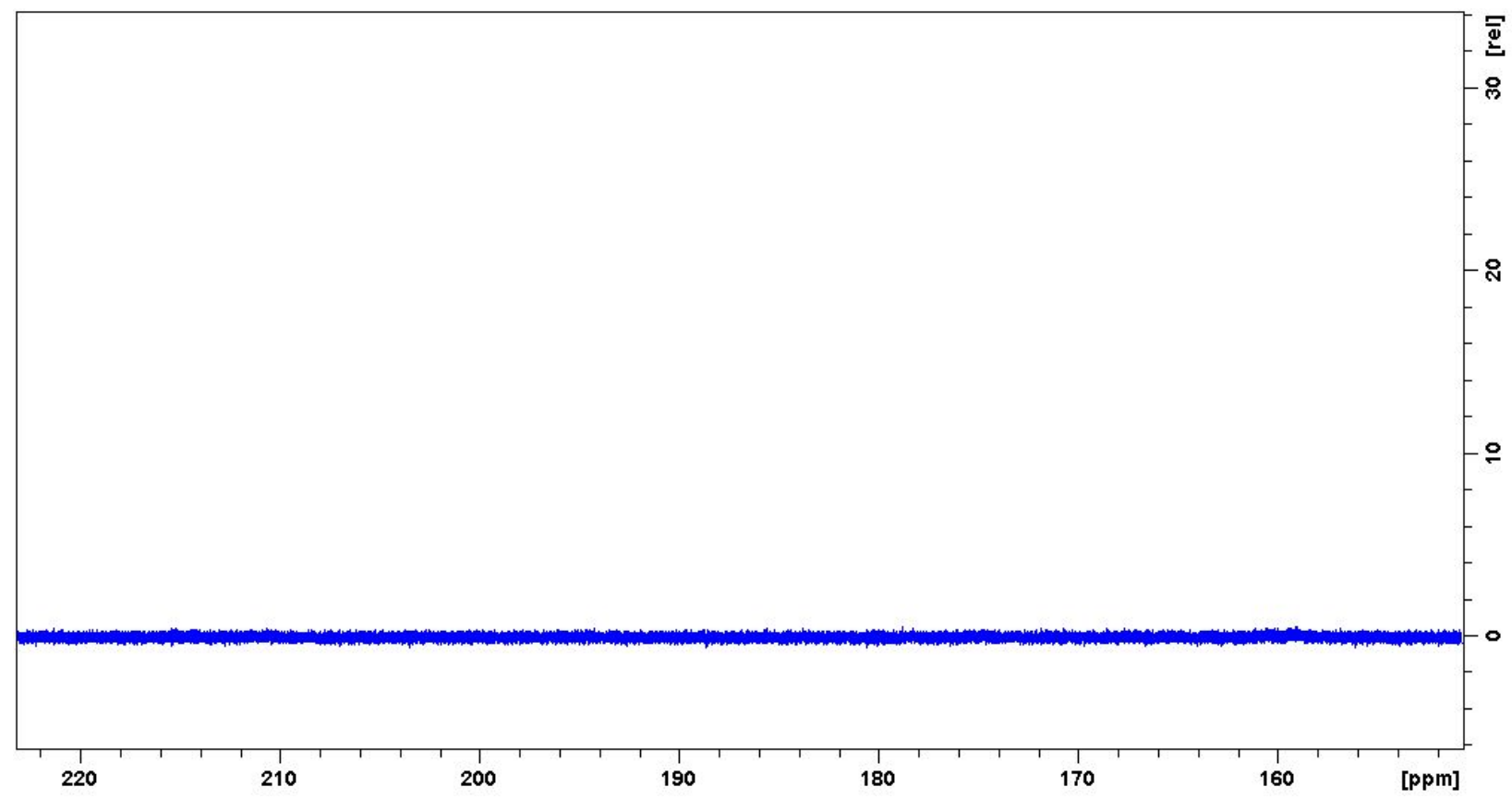

Fig. S14. ${ }^{13} \mathrm{C}$ qNMR (AV600, toluene- $d_{8}$ ) spectrum of 2 (carbonyl region) at $353 \mathrm{~K}$.

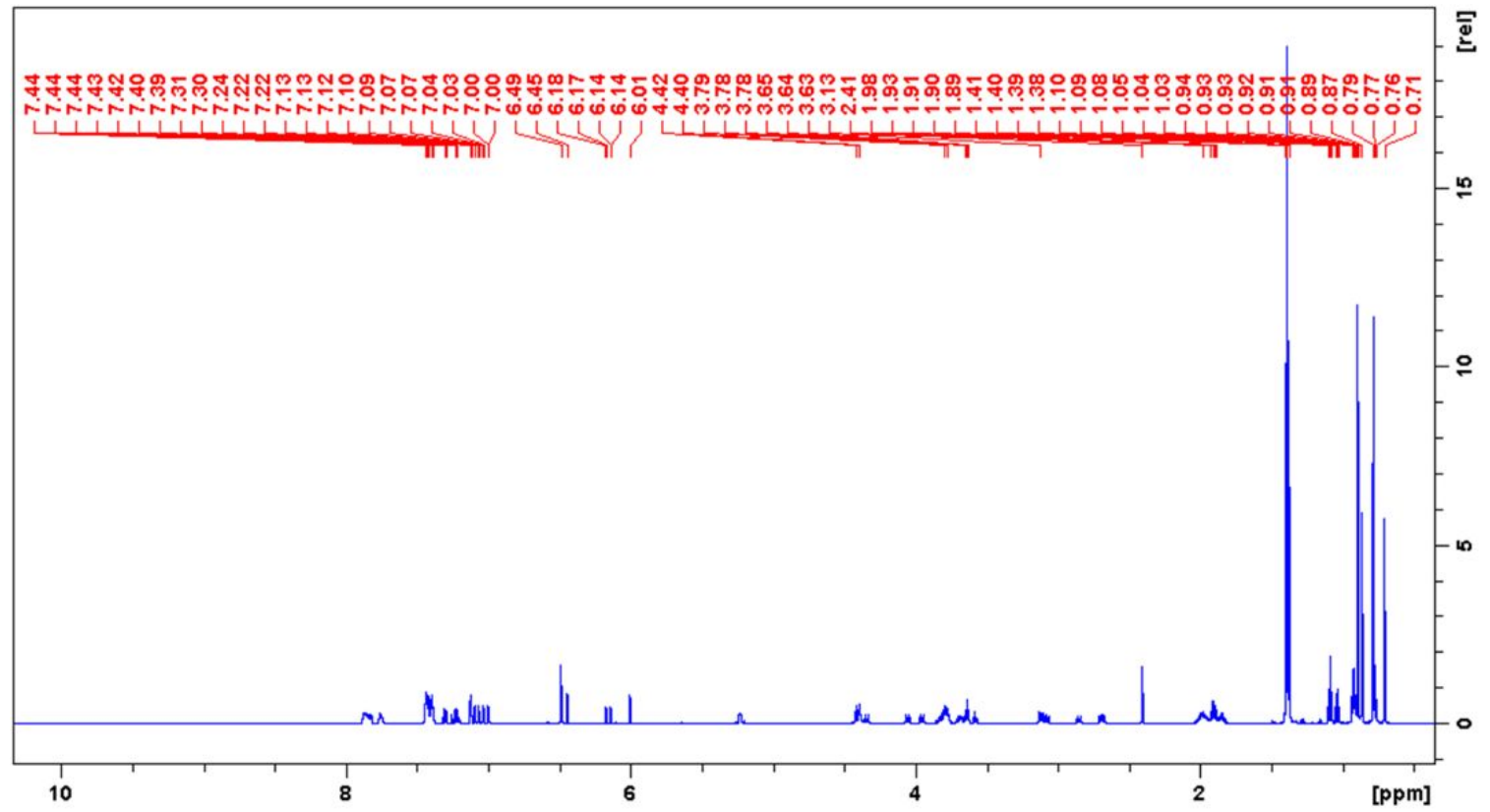

Fig. S15. ${ }^{1} \mathrm{H}$ NMR (AV600, $\mathrm{CDCl}_{3}$ ) spectrum of 3 at $293 \mathrm{~K}$. 


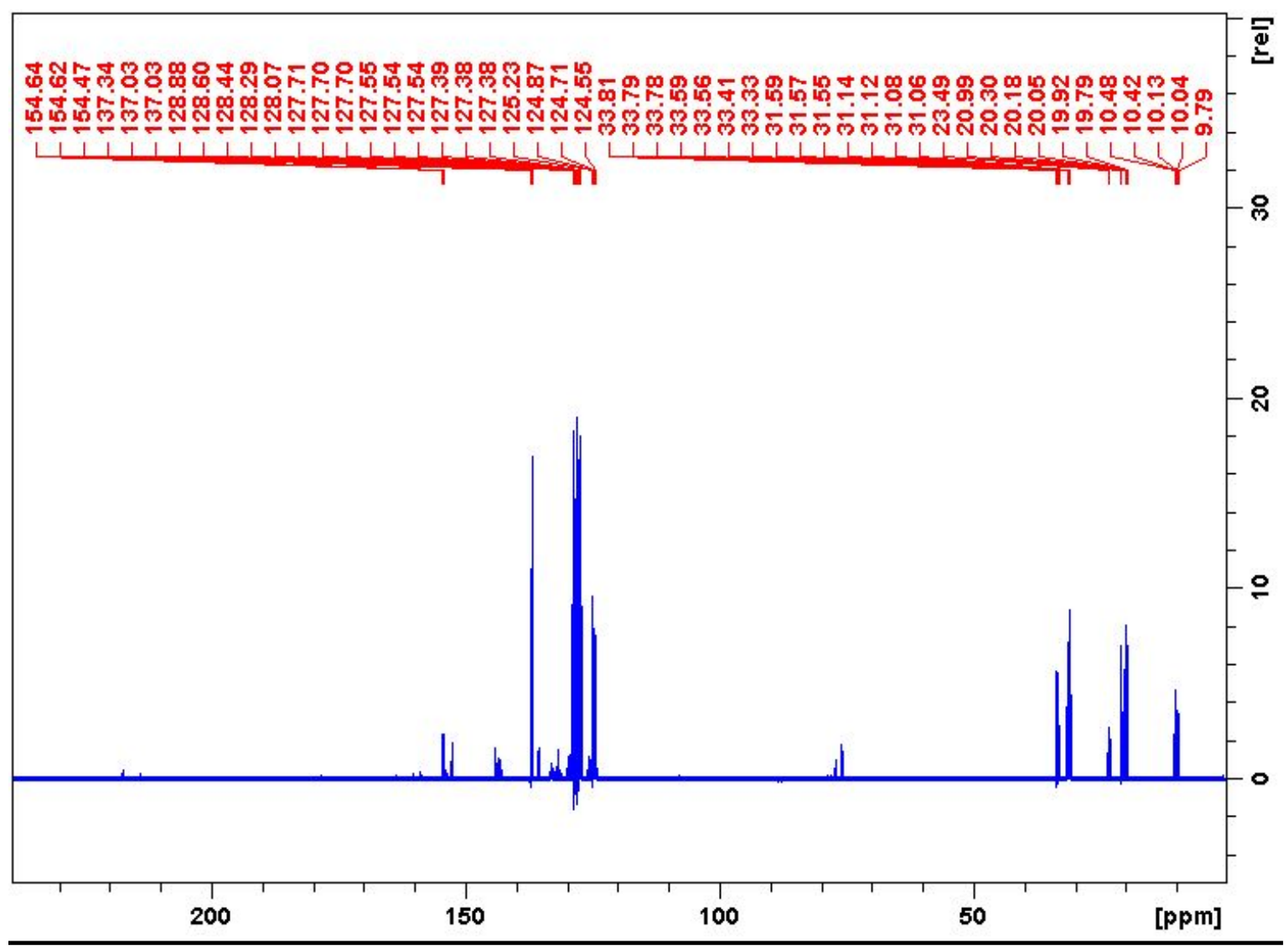

Fig. S16. ${ }^{13} \mathrm{C}$ qNMR (AV600, toluene- $d_{8}$ ) spectrum of 3 at $293 \mathrm{~K}$. 

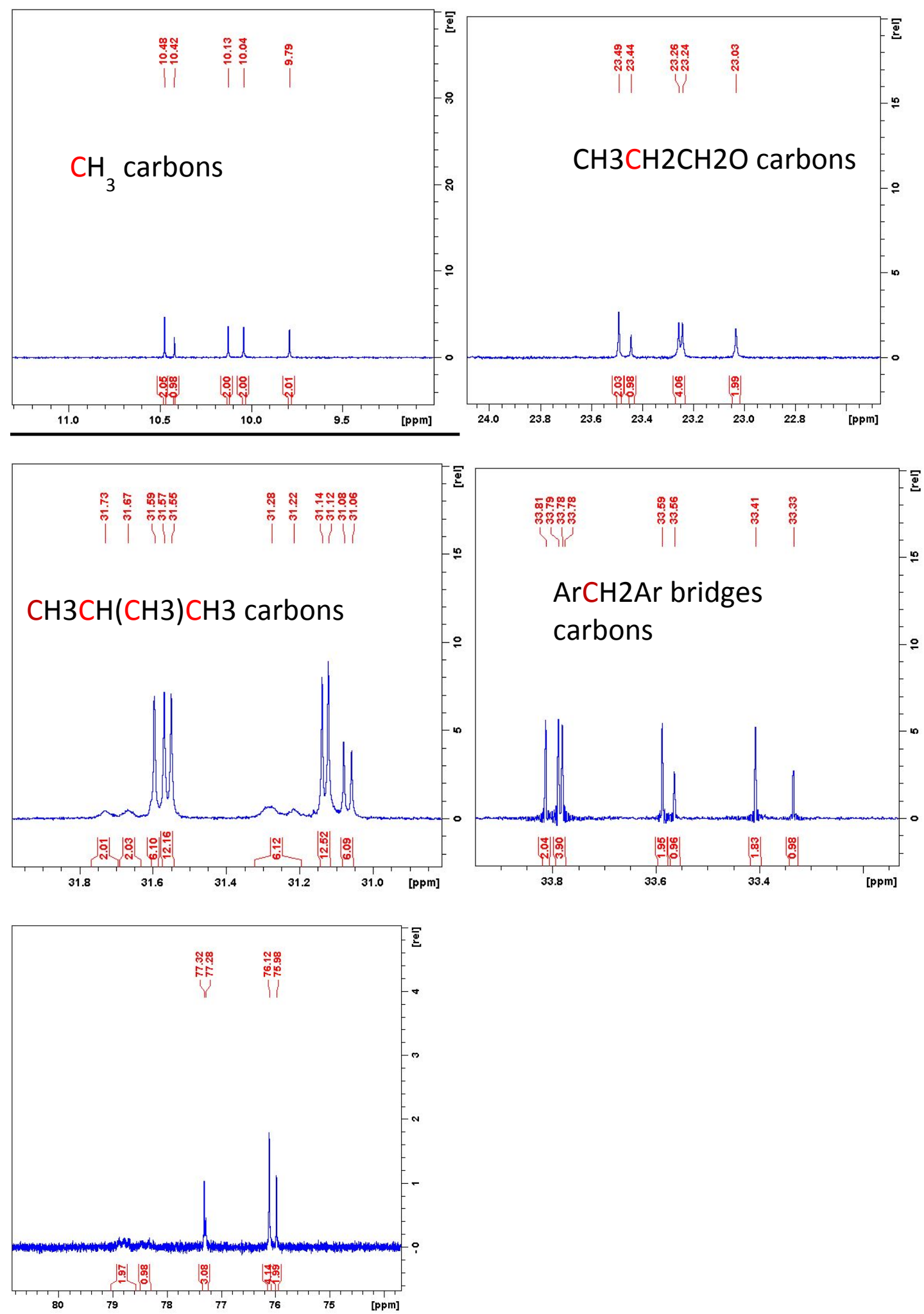

Fig. S17. ${ }^{13} \mathrm{C}$ NMR (AV600, toluene- $d_{8}$ ) spectrum of $\mathbf{3}$ (aliphatic region) at $293 \mathrm{~K}$, which is a blow up of data in Figure S12. 

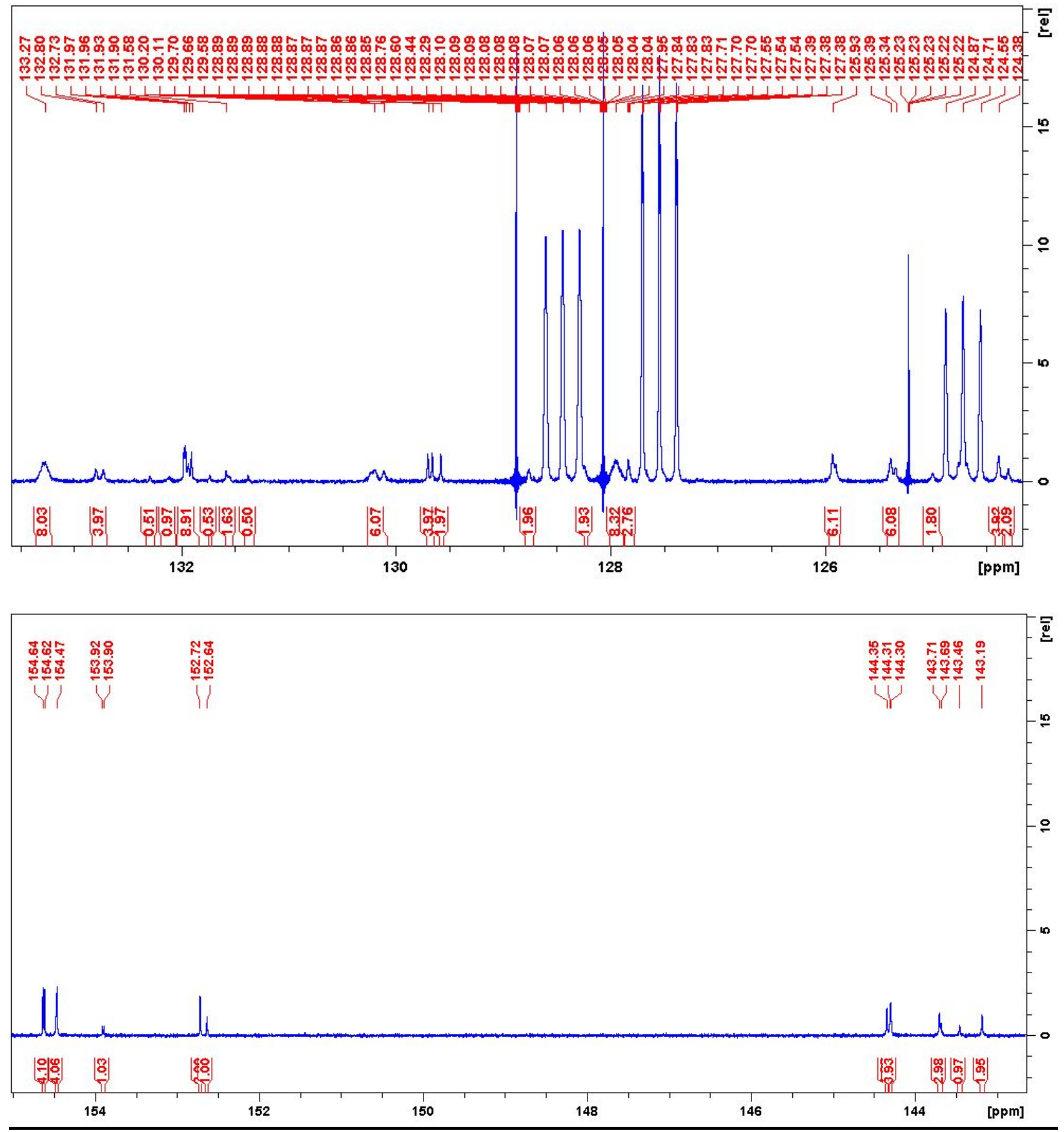

Fig. S18. ${ }^{13} \mathrm{C}$ qNMR (AV600, toluene- $d_{8}$ ) spectrum of $\mathbf{3}$ (aromatic region) at $293 \mathrm{~K}$. 


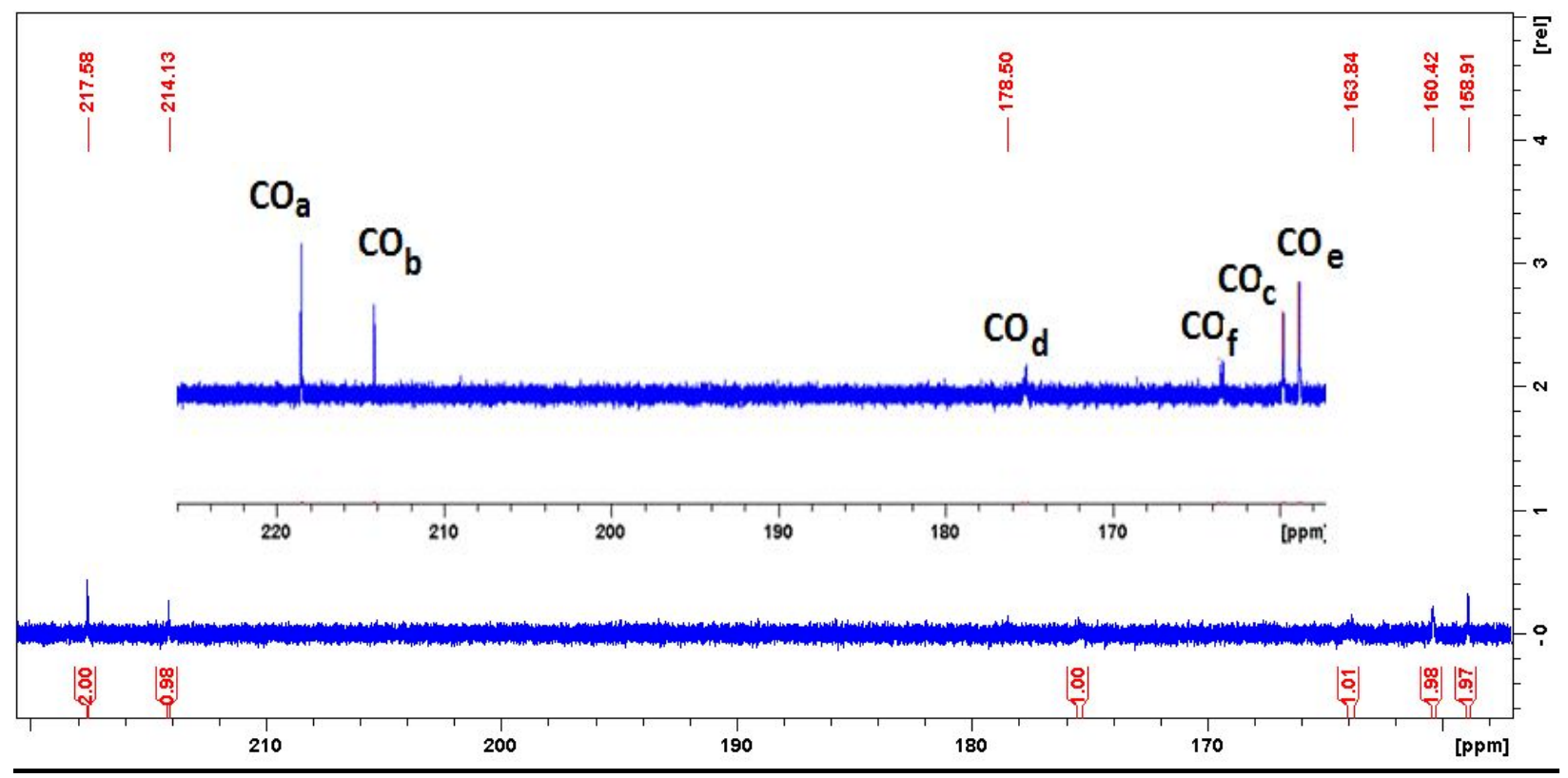

Fig. S19. ${ }^{13} \mathrm{C}$ qNMR (AV600, toluene- $d_{8}$ ) spectrum of $\mathbf{3}$ (carbonyl region) at $293 \mathrm{~K}$. Inset: Assignment of ${ }^{13} \mathrm{C}$ NMR spectrum of $\mathbf{3}$ (carbonyl region) in toluene- $\mathrm{d}_{8}$ at 293 $\mathrm{K}$.

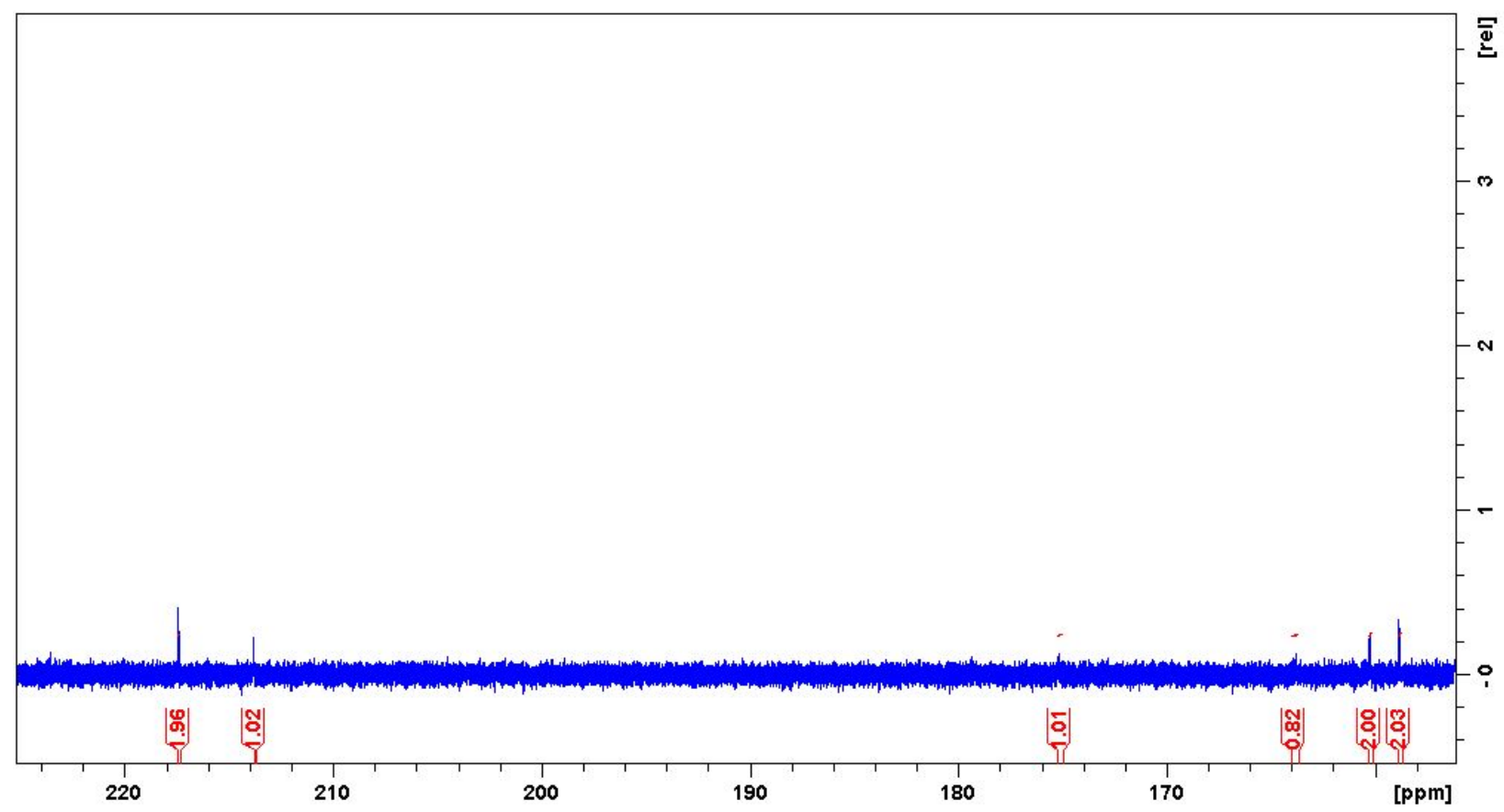

Fig. S20. ${ }^{13} \mathrm{C}$ qNMR (AV600, toluene- $d_{8}$ ) spectrum of $\mathbf{3}$ (carbonyl region) at $323 \mathrm{~K}$. 


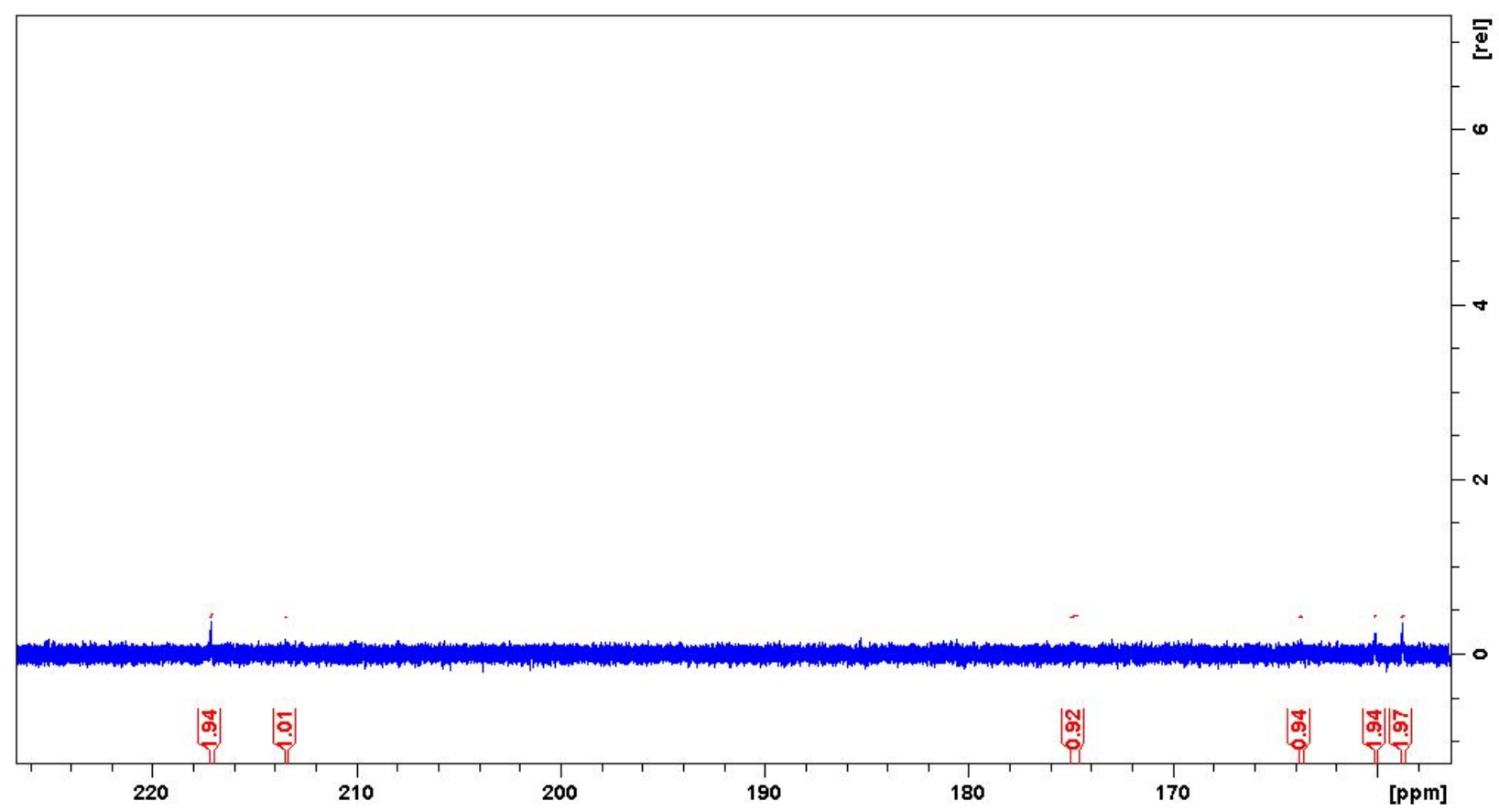

Fig. S21. ${ }^{13} \mathrm{C}$ qNMR (AV600, toluene- $d_{8}$ ) spectrum of $\mathbf{3}$ (carbonyl region) at $353 \mathrm{~K}$.

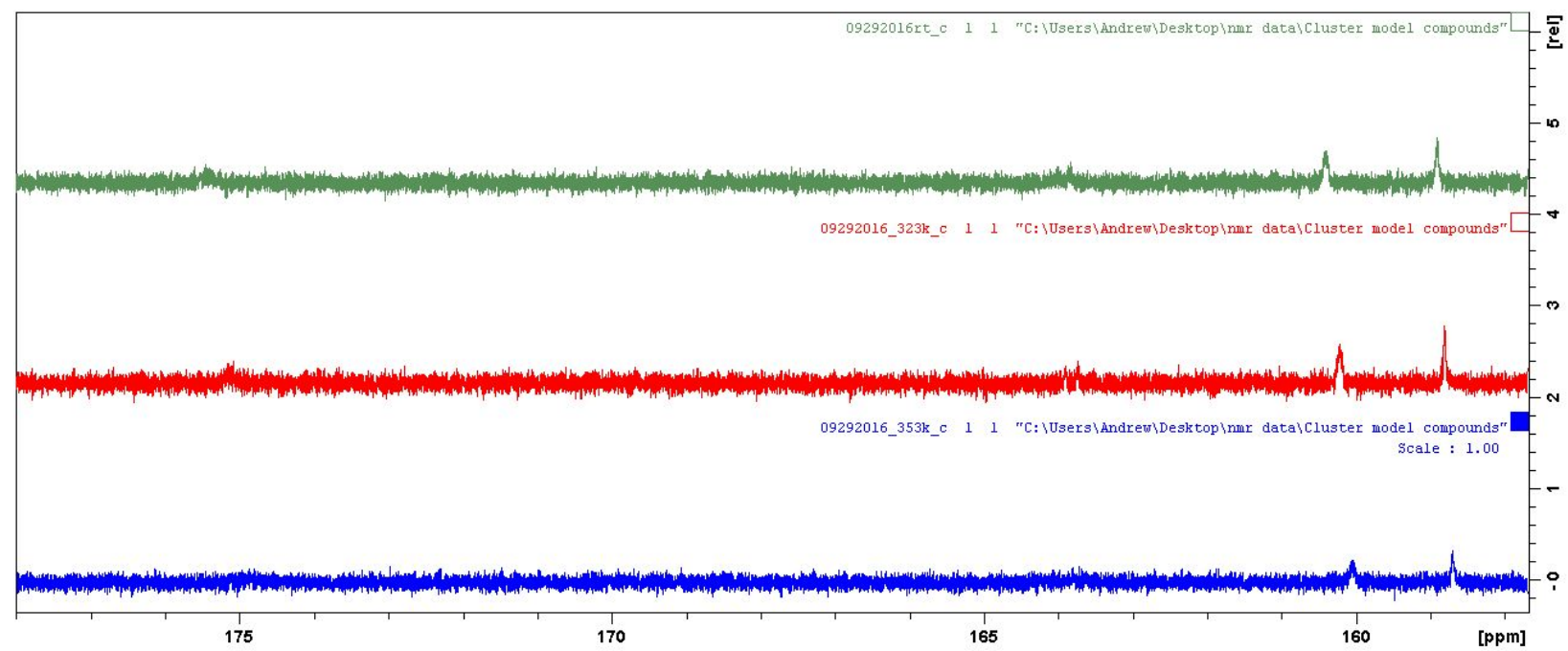

Fig. S22. ${ }^{13} \mathrm{C}$ qNMR (AV600, toluene- $d_{8}$ ) spectrum of 3 (carbonyl region) at $293 \mathrm{~K}$ (green), $323 \mathrm{~K}$ (red) and $353 \mathrm{~K}$ (blue). 

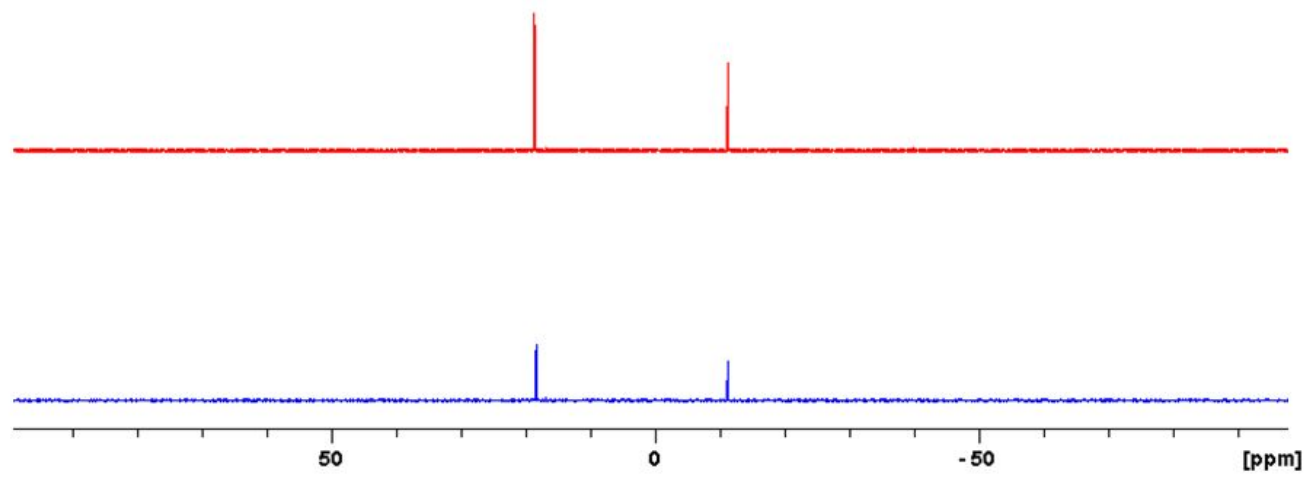

Fig. S23. ${ }^{31} \mathrm{P}$ VT NMR (AV600, toluene- $d_{8}$ ) spectrum of 3 at $293 \mathrm{~K}$ (red), 353K (blue).

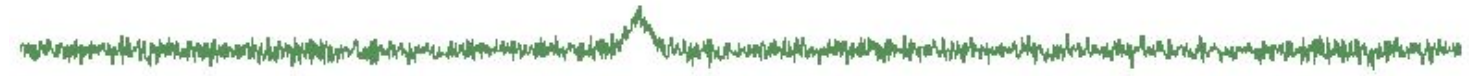
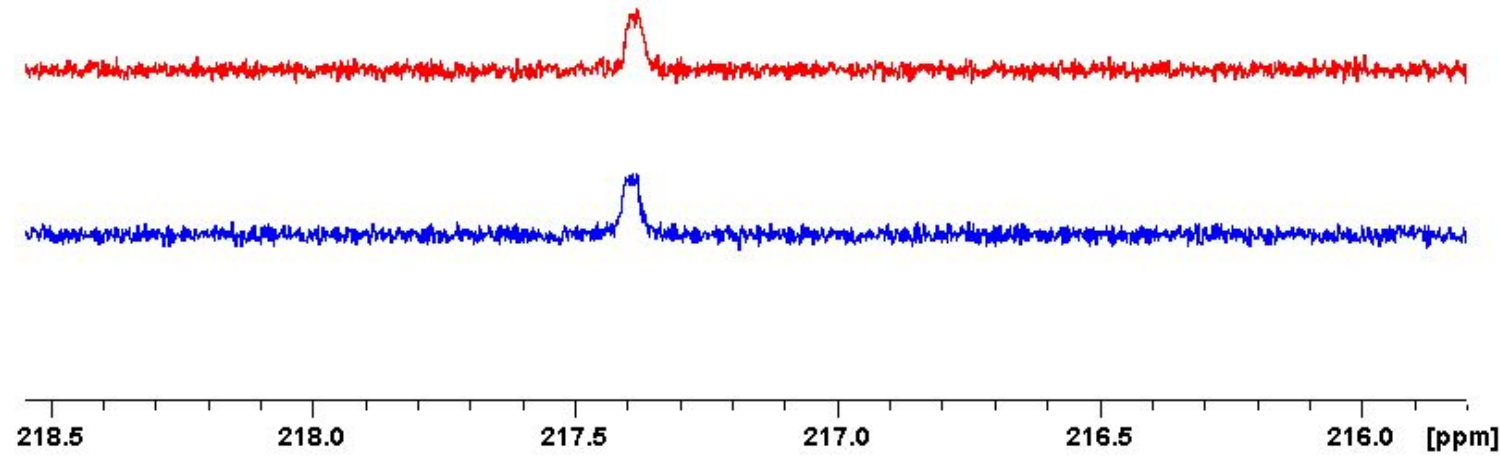

Fig. S24. ${ }^{13} \mathrm{C}$ VT qNMR (AV600, toluene- $d_{8}$ ) spectrum of $\mathbf{3}$ (line shape of bridging carbonyls at $293 \mathrm{~K}$ (blue), $323 \mathrm{~K}$ (red), $353 \mathrm{~K}$ (green). 


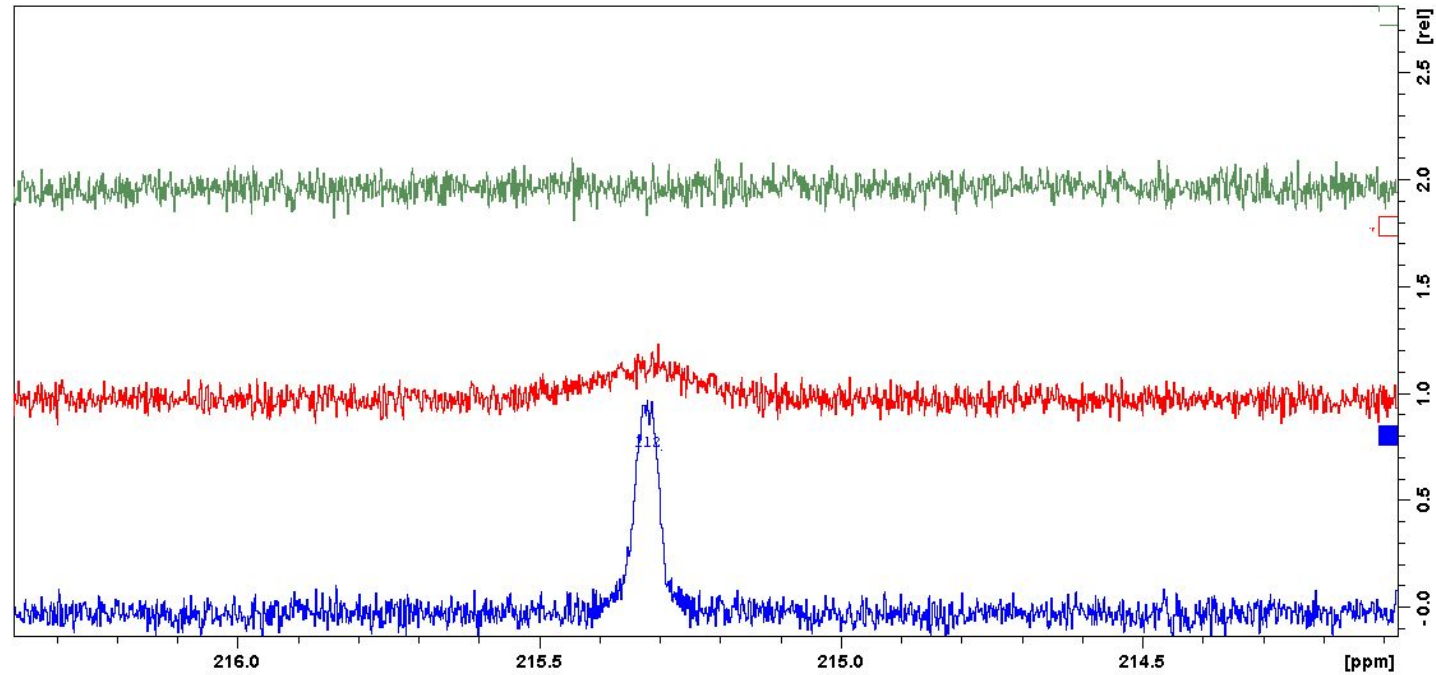

Fig. S25. ${ }^{13} \mathrm{C}$ VT NMR (AV600, toluene- $d_{8}$ ) spectrum of 2 (line shape of bridging carbonyls at $293 \mathrm{~K}$ (blue), $323 \mathrm{~K}$ (red), $353 \mathrm{~K}$ (green)).

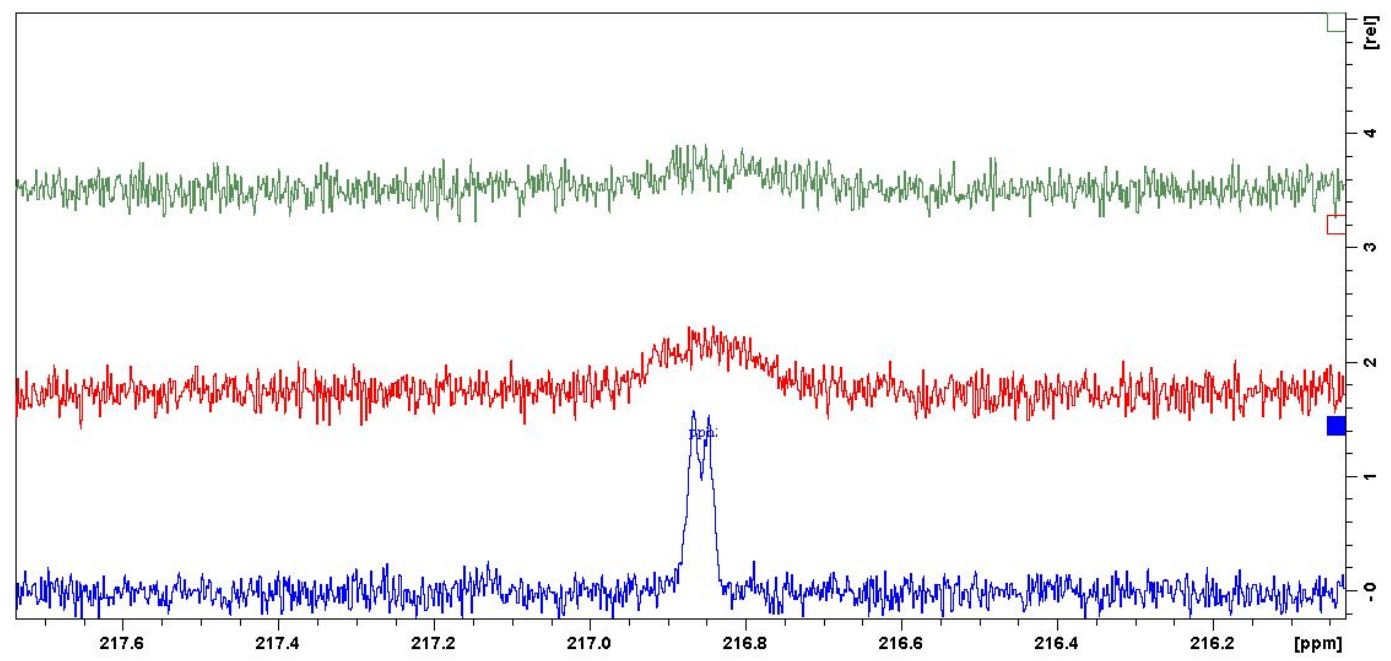

Fig. S26. ${ }^{13} \mathrm{C}$ VT NMR (AV600, toluene- $d_{8}$ ) spectrum of 1 (line shape of bridging carbonyls at $293 \mathrm{~K}$ (blue), $323 \mathrm{~K}$ (red), $353 \mathrm{~K}$ (green). 


\section{Calculation of rate constant $k$ of $\mathrm{CO}$ exchange}

The rate constant $k$ (unit: $\mathrm{s}^{-1}$ ) of $\mathrm{CO}$ exchange was calculated by using the general equation reported for slow exchange reactions (e.g., M. L. H. Green, L.-L. Wong, Organometallics 1992, 11, 2660-2668; E. Liepinsh, G. Otting, Magn. Reson. Med. 1996, 35, 30-42):

$$
k=\pi\left(v-v_{\text {base }}\right)
$$

where $v$ (unit: $\mathrm{Hz}$ ) is the half-height width of broadened NMR resonance at a high temperature and $v_{\text {base }}$ (unit: $\mathrm{Hz}$ ) is the half-height width of sharp NMR resonance at a low temperature. This equation and procedure were used to calculate rate constants in Table 2 of the manuscript, using data from Table 1, by assuming a lack of intramolecular CO exchange for clusters $\mathbf{1}-\mathbf{3}$ at $298 \mathrm{~K}$ based on the narrow line widths measured. 